\title{
Randy L. MADDOX, Jason E VICKERS, (eds.) The Cambridge Companion to John Wesley
}

Cambridge - New York, Cambridge University Press, 2010, 342 p.

\section{Pascale Gruson}

\section{(2) OpenEdition} Journals

Édition électronique

URL : http://journals.openedition.org/assr/22538

DOI : $10.4000 /$ assr.22538

ISSN : 1777-5825

Éditeur

Éditions de l'EHESS

Édition imprimée

Date de publication : 31 décembre 2010

Pagination : 9-242

ISBN : 9782713223013

ISSN : 0335-5985

Référence électronique

Pascale Gruson, « Randy L. MAdDox, Jason E vickers, (eds.) The Cambridge Companion to John

Wesley ", Archives de sciences sociales des religions [En ligne], 152 | octobre-décembre 2010, document 152-81, mis en ligne le 12 mai 2011, consulté le 21 septembre 2020. URL : http:// journals.openedition.org/assr/22538; DOI : https://doi.org/10.4000/assr.22538

Ce document a été généré automatiquement le 21 septembre 2020.

(C) Archives de sciences sociales des religions 


\section{Randy L. MADDOX, Jason E VICKERS, (eds.) The Cambridge Companion to John Wesley}

Cambridge - New York, Cambridge University Press, 2010, 342 p.

Pascale Gruson

\section{RÉFÉRENCE}

Randy L. MADDOX, Jason E VICKeRs, (eds.) The Cambridge Companion to John Wesley,

Cambridge - New York, Cambridge University Press, 2010, 342 p.

1 Le nom de John Wesley est évidemment associé au méthodisme dont on sait les développements importants en Angleterre, aux États-Unis, en Afrique, qu'il s'agisse de l'Armée du Salut et de son œuvre diaconale remarquable ou des multiples Églises évangéliques et pentecôtistes qui se réclament de cet héritage

2 Pour approcher ce mouvement de réveil et comprendre le débat passionnant qu'il a ouvert avec les modernités qu'il a côtoyées et dans lesquelles il s'est engagé, la lecture du volume de la série The Cambridge Companion to... consacré à Wesley est précieuse. Les auteurs qui y ont participé, professeurs de théologie, d'histoire des religions ou de littérature dans de grandes universités (dont certaines d'origine méthodiste) sont de sensibilités suffisamment différentes pour donner à voir un panorama large, nuancé et subtil. Point d'hagiographie dans ces pages, mais un regard ouvert sur un homme qui, né en 1703 et mort en 1791, fut le strict contemporain de la philosophie des Lumières, du contexte de modernisation et de sécularisation dont elle était l'une des dimensions fortes.

3 Il importait de souligner d'abord la simultanéité des mouvements de réveil protestant (piétisme, frères moraves, méthodisme) et des dynamiques de sécularisation sociale. Comme le montre Jeremy Gregory (Université de Manchester) dans l'article inaugural de ce volume, en étant attentif à des situations locales (dans les régions minières par 
exemple), en valorisant l'expérience vécue et les sentiments qui y sont attachés, en privilégiant l'intériorité, le méthodisme reconnaissait une certaine sécularisation de la société et y trouvait sa place, celle de venir en aide à ceux que l'industrialisation naissante en Angleterre déstabilisait. Il s'agissait là d'une attitude pragmatique, d'ailleurs assez courante dans l'Église d'Angleterre au sein de laquelle beaucoup de mouvements de dissent avaient déjà pris naissance(presbytériens, baptistes, congrégationalistes). Et, comme le rappelle Kenneth J. Collins (Asbury Theological Seminary), John Wesley, qui était né dans une famille de dissenters restés dans l'alma mater, n'a jamais quitté cette Église. Au moment où il suit à Oxford les études qui le forment au ministère pastoral, d'importants débats doctrinaux se développent autour du thème du salut par la grâce seule - ce point est remarquablement développé par David N. Hampton (Harvard Divinity School). Certains de ses proches amis se prononcent pour une interprétation strictement calvinienne, ce qui signifie que nul ne peut être assuré ici-bas de son salut, la vocation de chacun étant de travailler pour que resplendisse la gloire de Dieu. Mais il lui préfère l'interprétation adoucie qu'en avait donnée le théologien néerlandais, Jacob Arminius (1560-1609). En l'occurrence, il trouve dans la lecture de l'Évangile les ressources qui orientent l'action d'aujourd'hui vers l'œuvre bonne et ouvrent aux promesses du salut. Cette interprétation donne plus d'assurance au bien-fondé des choix de la vie quotidienne. Wesley a très souvent prêché sur la première épître de Jean qui l'étaye particulièrement et d'une manière générale, il a, dans sa prédication, privilégié une actualisation de l'évangile permettant de donner des indications concrètes sur ce qu'implique «l'amour du prochain» dans la vie quotidienne, encourageant ainsi diverses formes de diaconie. C'est de cet engagement toujours perfectible qu'est née la dissidence raisonnée du méthodisme.

4 Resté longtemps célibataire, Wesley avait choisi d'être pasteur itinérant et l'une de ses premières initiatives réformatrices fut d'organiser, là où il se trouvait et hors des lieux de culte proprement dit, des assemblées de fidèles dans le propos de lire ensemble l'évangile. Par définition, ces assemblées ont une certaine spontanéité; les méditations et les prières peuvent être confiées à des laïcs, y compris des femmes. Dans les premiers temps, elles doivent être complétées par l'assistance régulière aux cultes de l'Église d'Angleterre. Mais après un voyage aux États-Unis, où il avait eu une rencontre décisive avec une communauté de frères moraves, il organise le dissent de manière plus affirmée. Les assemblées méthodistes pratiquent désormais des cultes dans lesquels la liturgie et l'hymnologie (grâce à son frère Charles) sont modernisées. Le Book of Prayers, pilier de l'Église d'Angleterre, est modernisé, ce qui veut dire aussi de langue plus accessible. John Wesley se sent habilité à nommer des pasteurs sans en référer à la hiérarchie anglicane aux fins de les envoyer dans diverses missions, en particulier aux États-Unis. Ce sont ces missions qui se sont de plus en plus éloignées de la tradition anglicane tandis que le débat sur le salut par la grâce y était moins théologique et plus utilitariste.

5 L'engagement de Wesley dans une modernisation de l'Église s'est accompagné de beaucoup d'autres activités, dont le journal qu'il a tenu régulièrement et l'abondance de sa correspondance permettent de prendre la mesure. Isabel Rivers (University of London) le montre dans sa compétence d'éditeur: outre des pères de l'Église, elle a édité une histoire de l'Angleterre, mais aussi les œuvres de Pascal ou de Madame Guyon, et bien d'autres encore. Randy L. Maddox (Duke University) souligne l'intérêt qu'il a porté à Francis Bacon et à Newton. Il est en particulier tout à fait persuadé de l'importance de l'expérimentation dans le développement du progrès scientifique. Deborah Madden 
(Université d'Oxford) se penche sur son rôle dans l'amélioration des soins et des conditions d'hygiène de vie.

D'une manière générale, les contributions mettent en évidence le pragmatisme confiant de Wesley et la variété des curiosités qui ont nourri ses exigences perfectionnistes. Ceci étant, l'héritage de ce pionnier est extrêmement variable. Daniel Halévy disait qu'il avait permis aux Anglais d'éviter une révolution. Peut-être... On peut en tout cas dire qu'il fut admirable dans le souci des autres et de leur vie quotidienne; c'est l'œuvre d'une femme comme Phoebe Palmer (1807-1874): après avoir perdu presque tous ses enfants, elle s'était engagée dans une prédication de consolation des autres centrée sur l'invitation à la sanctification et au perfectionnement (concret et pratique). Elle a par la suite «milité» en faveur du ministère féminin. C'est aussi l'œuvre de Catherine et William Booth qui ont fondé l'Armée du Salut. Ce sont aussi des développements philosophiques: Emerson et Thoreau (tous deux fils de pasteurs) ont sûrement tiré parti de ce terreau (le perfectionnisme entre autres). Mais il a été tout autant générateur de positions moins avisées. Le rayonnement de la réforme méthodiste reste dans les limites posées par son interprétation initiale du salut par la grâce. Celle-ci privilégie l'action et le service social dans toutes leurs urgences particulières et pratiques. Quant à ce qui aurait provoqué ces situations d'urgence, elle se considère comme peu compétente, voire peu disposée, à en traiter. C'est une position que Trœltsch avait admirablement exposée dans Die Soziallehre der christlichen Kirchen und Gruppen. 